\title{
Decomposition Analysis on the Factors of Energy Consumption Growth in Beijing-Tianjin-Hebei
}

\author{
Yanmei $\mathrm{Li}^{1,}$, , Zhongyuan $\mathrm{Li}^{1, \mathrm{~b}}$ and Liyun Sun ${ }^{1, \mathrm{c}}$ \\ ${ }^{1}$ Institute of Circular Economy, Beijing University of Technology, 100 Pingleyuan Street, Chaoyang \\ Distric, Beijing, 100124, China. \\ a liyanmei1979@sina.cn, ${ }^{b}$ tongyizhongyuan@126.com, ${ }^{c}$ sly511@sina.cn
}

\begin{abstract}
Keywords: decomposition analysis; energy consumption growth; Logarithmic Mean Division Index; Beijing-Tianjin-Hebei.

Abstract. We decompose energy consumption of Beijing-Tianjin-Hebei by Logarithmic Mean Division Index. Our results show that economic development, population and industrial structure promote energy consumption increase, energy intensity play a role in reducing energy consumption, energy structure change almost has no impact on energy consumption in the Beijing-Tianjin-Hebei economic belt; and there are some differences among Beijing, Tianjin and Hebei. The results suggest that Beijing-Tianjin-Hebei economic belt should pay attention to the potential effect of population growth and industrial structure, yet the effect of energy structure may not be as significant as often assumed. We offer specific policy recommendations with respect to reducing and optimizing energy consumption in the process of economic integration.
\end{abstract}

\section{Introduction}

Regional integration has been a major trend for national scale economies and comparative advantages. In 2014, China augmented the development of the Beijing-Tianjin-Hebei economic belt and has since been featured it as a national strategy to accelerate and consolidate the country's economy on a regional basis. Accounting for $10.48 \%$ of the GDP in 2014, the region will play an even greater role in Chinese economy. At the same time, however, the integration of the regional economy also bear serious consequences on energy consumption, per 10,000 Yuan GDP of Beijing-Tianjin-Hebei economic belt consumed 1.55 Mtce (Million ton coal equivalent) from 1995 to 2013, higher than the national level (1.37Mtce). This paper intends to explore the reasons of energy consumption growth by decomposition analysis method in Beijing-Tianjin-Hebei economic belt from 1995 to 2013.

According to existing studies, there are many factors affecting energy consumption, such as population[1], production structure [2], industrial structure[3], energy intensity [4], technology [5, 6], energy efficiency [7], household structure[8], energy price and government expenditure [9]. Because there were too many factors affecting energy consumption, some researchers, based on influence effect, divide all them into amount effect, structure effect and intensity effect [10]. We divide the factors affecting the growth of energy consumption into five, including economic growth, population, industrial structure, energy intensity, and energy structure.

Current methods on decomposing energy consumption mainly consisted of SDA (Structure Decomposition Analysis) and IDA (Index Decomposition Analysis). SDA can be realized by Input-Output table [11, 12]. Naturally, SDA has a character of data intensity and calculation complexity. IDA experienced an evaluation by the endeavours of many scholars $[13,14]$; And LMDI of IDA is popular and appropriate on decomposing energy consumption in the region level [15]. Therefore, we decompose energy consumption of the Beijing-Tianjin-Hebei region by LMDI (Logarithmic Mean Division Index) method.

The rest of this paper is organized as follows. Section 2 reports methodology on decomposing energy consumption, Section 3 investigates decomposition results and does discussion, and Section 4 gives main conclusions and policy implications that benefit to save energy on the integration development of Beijing-Tianjin-Hebei economic belt. 


\section{Methodology}

Decomposition method. Energy consumption of Beijing-Tianjin-Hebei economic belt can be defined as. Annual energy consumption of the region can be expressed as Eq. (1).

$$
\begin{array}{r}
E_{B}=\sum_{i} \Sigma_{j} P_{B} * \frac{G_{E}}{p_{E}} * \frac{G_{B i}}{G_{E}} * \frac{E_{E i}}{G_{B i}} * \frac{E_{B i j}}{E_{B i}}=\sum_{i} \sum_{j} p_{B} * w_{B} * s_{B i} * u_{B i} * e_{B i j} \\
\left\{\begin{array}{l}
1 \leq i \leq 3 \\
1 \leq j \leq 5
\end{array}\right.
\end{array}
$$

In Eq. (1), we define $P_{B}$ as permanent resident population, $G_{B}$ as GDP, $G_{E i}$ as GDP of industry 'i', $E_{E i}$ as energy consumption of industry 'i', $E_{E i j}$ as energy consumption of industry 'i' based on fuel 'j'. Meanwhile, we assume $p_{B}=P_{E}, p_{B}$ denotes total permanent resident population, $w_{B}=\frac{G E}{P_{B}}$, $w_{B}$ is GDP of per person, and we also treat it as economic development of this region; $s_{E i}=\frac{G_{B i}}{G_{B}}, s_{E i}$ is industrial share of industry 'i'; $u_{B \bar{i}}=\frac{E_{B i}}{G_{B i}}$, and $u_{B \bar{i}}$ is energy intensity of industry 'i'; $e_{B i j}=\frac{E_{E i j}}{E_{B i}}, e_{B i j}$ represents proportion of fuel ' $\mathrm{j}$ ' in industry ' $\mathrm{i}$ '.

Decomposition of energy consumption in Beijing-Tianjin-Hebei economic belt can be done by additive form of LMDI, as shown by Eq. (2).

$$
\begin{aligned}
& \Delta E_{B}=E^{t}-E^{0}=\Delta E_{p o p}+\Delta E_{g d p}+\Delta E_{g t v}+\Delta E_{i n t}+\Delta E_{\text {qug }} \\
& \Delta E_{\text {pop }}=\Sigma_{n} L\left(E_{n}^{t}, E_{n}^{0}\right) \ln \left(\frac{p^{2}}{p^{0}}\right) \\
& \Delta E_{g u p}=\Sigma_{n} L\left(E_{n}^{t}, E_{n}^{0}\right) \ln \left(\frac{w^{t}}{w^{0}}\right) \\
& \Delta E_{\text {str }}=\Sigma_{\mathrm{n}} L\left(E_{n}^{t}, E_{n}^{0}\right) \ln \left(\frac{s^{t}}{s^{2}}\right) \\
& \Delta E_{\text {int }}=\Sigma_{n} L\left(E_{n}^{t} E_{n}^{0}\right) \ln \left(\frac{u^{t}}{u^{0}}\right) \\
& \Delta E_{e n e}=\Sigma_{n} L\left(E_{n}^{t}, E_{n}^{0}\right) \ln \left(\frac{\theta^{t}}{\theta^{0}}\right) \\
& L\left(E_{i}^{T}, E_{i}^{0}\right)=\left\{\begin{array}{cc}
\frac{E_{i}^{t}-E_{i}^{0}}{\ln E_{i}^{T}-\ln E_{i}^{0}}, E_{i}^{0} \neq E_{i}^{t} \\
E_{i}^{t} \text { or } E_{i,}^{0}, \quad E_{i}^{0}=E_{i}^{t} \\
t=1,2_{1}, \ldots, 19 .
\end{array}\right.
\end{aligned}
$$

In Eq. (2), $\Delta E_{B}$ is variation of energy consumption from year ' 0 ' to year ' $t$ ' in Beijing-Tianjin-Hebei economic belt. According to Eq. (1), we can divide all the changes into the following five effects. In Eq. (3), we defined $\Delta E_{\text {pop }}$ as population effect, which means the vary of population that leads to the variation of energy consumption in Beijing-Tianjin-Hebei economic belt; in Eq. (4), we treat $\Delta E_{g d p}$ as economic activities that lead to the variation of energy change in this region; in Eq. (5), we regard $\Delta E_{z t r}$ as industrial structure effect, which means the variations of primary industry, secondary industry and tertiary industry that lead to the change of energy consumption; in Eq.(6), we define $\Delta E_{\text {im }}$ as intensity effect, namely the variation of energy intensity of industry "i" that leads to the change of energy amount; in Eq. (7), we regard $\Delta E_{\text {w }}$ as energy structure effect, and it equals to change of main sorts of energy proportion that contributes to the energy consumption. $\mathrm{L}\left(\boldsymbol{E}_{i}^{t}, E_{i}^{0}\right)$ is calculated by formula (8). $E_{i}^{z}$ is energy consumption of sector " $\mathrm{i}$ " in year " $\mathrm{t}$ ", $E_{i}^{0}$ is energy consumption of sector "i" in primary year.

Data sources. In this paper, time series data are used for the purpose of analyzing and decomposing energy consumption in Beijing-Tianjin-Hebei economic belt from 1995 to 2013. Data of GDP and population are from National Bureau of statistical of People's Republic of China, benchmark of GDP referenced to the price of 1978. Data of energy consumption of primary industry, secondary industry and tertiary industry come from Energy balance table of each region, the exchange coefficients from physical quantity to standard quantity of each fuel reference to national standard of China. Energy structure of Beijing-Tianjin-Hebei economic belt is consisted by coal, electricity, petroleum, heat, natural gas and others. 


\section{Results and discussion}

Firstly, we decompose energy consumption in Beijing-Tianjin-Hebei economic belt. Secondly, we explore driving factors of energy consumption in Beijing, Tianjin and Hebei, respectively.

Results in Beijing-Tianjin-Hebei economic belt. Table 1 shows the results of decomposing energy consumption in Beijing-Tianjin-Hebei economic belt from 1995 to 2013. We can observe some conclusions from table 1.

Table 1 Results of decomposition of Beijing-Tianjin-Hebei economic belt (Mtce)

\begin{tabular}{ccccccc}
\hline Year & $\triangle$ Total & $\triangle$ Population & $\begin{array}{c}\Delta \text { Economic } \\
\text { development }\end{array}$ & $\begin{array}{c}\Delta \text { Industrial } \\
\text { Structure }\end{array}$ & $\begin{array}{c}\Delta \text { Energy } \\
\text { Intensity }\end{array}$ & $\begin{array}{c}\Delta \text { Energy } \\
\text { Mix }\end{array}$ \\
\hline $1995-1996$ & -129.94 & 78.75 & 1206.37 & 65.49 & -1480.46 & -4.01 \\
$1996-1997$ & 440.53 & 33.50 & 1216.66 & 55.10 & -864.52 & -10.24 \\
$1997-1998$ & -625.83 & 68.23 & 998.12 & 40.17 & -1731.02 & -33.93 \\
$1998-1999$ & 1152.92 & 76.84 & 992.15 & 69.30 & 16.32 & 0.57 \\
$1999-2000$ & 863.91 & 288.55 & 929.69 & 43.40 & -397.72 & 0.30 \\
$2000-2001$ & 372.03 & 70.95 & 1160.33 & 20.28 & -879.50 & 1.09 \\
$2001-2002$ & 1298.61 & 117.09 & 1273.77 & 33.79 & -126.01 & 1.91 \\
$2002-2003$ & 1708.86 & 118.88 & 1685.64 & 99.84 & -195.31 & 0.35 \\
$2003-2004$ & 1823.12 & 163.39 & 2142.83 & 114.48 & -597.28 & 0.62 \\
$2004-2005$ & 3894.54 & 226.41 & 2287.83 & 96.01 & 1284.67 & 6.85 \\
$2005-2006$ & 1852.83 & 341.27 & 2573.11 & 87.73 & -1149.08 & 0.52 \\
$2006-2007$ & 1776.84 & 408.63 & 2846.23 & 50.78 & -1528.80 & 0.56 \\
$2007-2008$ & 620.23 & 531.22 & 2098.11 & -21.01 & -1988.05 & 0.66 \\
$2008-2009$ & 1967.38 & 503.90 & 2515.34 & 79.55 & -1131.17 & 0.75 \\
$2009-2010$ & 418.58 & 917.75 & 2713.87 & 135.03 & -3348.02 & 0.29 \\
$2010-2011$ & 2987.74 & 454.40 & 2993.82 & 99.34 & -559.50 & 1.26 \\
$2011-2012$ & 1255.34 & 468.93 & 2797.10 & 90.27 & -2100.91 & 1.21 \\
$2012-2013$ & 400.85 & 455.14 & 2523.07 & 45.63 & -2622.78 & 0.20 \\
Mean & 1226.58 & 295.77 & 1941.89 & 66.95 & -1077.73 & -1.72 \\
\hline
\end{tabular}

(1) Variations of population, economic development and industrial structure play a positive effect on promoting energy consumption in Beijing-Tianjin-Hebei economic belt. Average change of energy consumption, population effect, economic development effect and industrial structure effect are 1,226.58Mtce, 295.77Mtce, 1,941.89Mtce and 66.95Mtce from 1995 to 2013, respectively. And reasons can be attributed to the following aspects. a) Rapid urbanization promotes energy consumption of population. Average urbanization of Beijing-Tianjin-Hebei economic belt was $72.14 \%$ in 2013, and permanent resident in this region is 10.9198 million, higher urbanization equals to lifestyle of citizens transforms from low energy activities to high energy ones. Such as, more use of cars, more demand of houses, besides, more fundamental infrastructure ought to be provided by the local government to satisfy the demand. b) Industrial structure of this area experiences a process of industrialization, development of this region is mainly supported by energy intensive industry.

(2) Changes of energy intensity and energy structure incur negative influence on energy consumption. Energy intensity and energy structure decreased 1,077.73Mtce and 1.72Mtce, averagely, from 1995 to 2013. As empirical analysis of this area illustrates energy intensity has a great function of decreasing energy consumption, for technology progressive and other factors all boost the reduction of energy intensity. In 2013, according to the national bureau of statistics of China, investment of R\&D (research and development) in this region was 7.46 million Yuan, accounting almost $9 \%$ of the nation amount, and energy structure in this region experienced a process of optimization.

(3) Economic development has the strongest force on increasing energy consumption, while energy structure produces the weakest function on influencing energy consumption in 
Beijing-Tianjin-Hebei economic belt. Annual economic development incurring to energy consumption ranges from 930Mtce to 3000Mtce, while the effect of energy structure varies between -1Mtce and 24Mtce. All of these illustrate economic development in this district is still energy driving, so it has a long way for this region to transfer economic development from energy-driving to technology-driving or science-driving.

Results among Beijing, Tianjin and Hebei. Results of decomposing energy consumption inner Beijing, Tianjin and Hebei (table 2) are shown in table 2.

Table 2 Results of decomposition of Beijing, Tianjin and Hebei in 1995-2013(Mtce)

\begin{tabular}{lcccccc|}
\hline & Total & Population & $\begin{array}{c}\text { Economic } \\
\text { Development }\end{array}$ & $\begin{array}{c}\text { Industrial } \\
\text { Structure }\end{array}$ & $\begin{array}{c}\text { Energy } \\
\text { Intensity }\end{array}$ & $\begin{array}{c}\text { Energy } \\
\text { Structure }\end{array}$ \\
\hline Beijing & 122.65 & 133.74 & 280.41 & -0.3 & -291.04 & -0.06 \\
Tianjin & 185.68 & 95.36 & 337.15 & -4.43 & -242.33 & 0.19 \\
Hebei & 918.26 & 97.43 & 1533.35 & 46.4 & -758.49 & -1.19 \\
\hline
\end{tabular}

(1) Energy consumption in Hebei exceeded the sum of Beijing and Tianjin, and energy consumption in Hebei was mainly driven by economic development. Average growth amount of energy consumption in Beijing, Tianjin and Hebei were 122.6Mtce, 185.7Mtce and 918.3Mtce from 1995 to 2013, respectively. Above growth is triggered by economic development were 280.4Mtce, 337.2Mtce and 1533.3Mtce in Beijing, Tianjin and Hebei, respectively.

(2) Population in Beijing has a stronger strength on promoting energy consumption comparing to it in Tianjin and Hebei. Population effect in above three areas were 133.7Mtce, 95.4Mtce and 97.4Mtce, respectively.

(3) Energy intensity of Hebei is superior comparing to it in Beijing and Tianjin. Effect of energy intensity of Hebei, Beijing and Tianjin were 758.5Mtce, 291Mtce and 242.3Mtce, respectively.

(4) Industrial structure change of Hebei promotes energy growth, but it is not effective in Beijing and Tianjin. Effect of industrial structure change of Beijing, Tianjin and Hebei were -0.3Mtce, -4.4Mtce and 46.4Mtce, respectively. This phenomenon illustrates Hebei is still going on industrialization process.

(5) Energy structure adjustment of Beijing, Tianjin and Hebei are all too faint on influencing energy consumption, optimization of energy structure does not achieve remarkable consequence.

\section{Conclusions and policy implications}

Conclusions. Energy consumption plays a significant role in the integration process of Beijing-Tianjin-Hebei economic belt. This paper investigates the reasons of energy consumption increase of Beijing-Tianjin-Hebei economic belt from 1995 to 2013. Furthermore, inner differences are analyzed for deeper recognition. According to the results of this paper finds, main conclusions can be attributed as the following points.

(1) In Beijing-Tianjin-Hebei economic belt, economic development promotes energy consumption increase; industrial structure and population have weak force on increasing energy consumption; energy intensity is remarkable on reducing energy consumption; energy structure change almost has no impact on energy consumption.

(2) Among Beijing, Tianjin and Hebei, the effect of some factors is same, such as population, economic development and energy intensity; the effect of other factors is opposite, including industrial structure and energy structure.

Policy implications. Based on empirical findings, we present following policy implications.

(1) The results of this study show that economic development will increase energy consumption, so controlling growth rate other than reducing total energy consumption is meaningful to Beijing-Tianjin-Hebei economic belt, for economic development of this district will not stagnate in the near future. Only Beijing has transferred its economic development from extensive form to intensive one, so Beijing ought to share its experience with Tianjin and Hebei. Tianjin and Hebei 
should pay more attention to develop intensive economy, such as outdate older production equipment, improve per unit added GDP by the application of advanced technology, migrate energy intensive industry, especially secondary industry, to west China.

(2)In order to prevent population growth going further on increasing energy consumption, Beijing and Tianjin should control its permanent residents, optimize the layout of the cities and improve energy-saved awareness of citizens; for Hebei had an urgent demand of urbanization, Hebei ought to plan city infrastructure scientifically, avoid expanding cities scale or pursuit amount blindly.

(3)Industrial restructuring can effectively reduce energy consumption. So Beijing-Tianjin-Hebei economic belt, especially, Tianjin and Hebei could develop tertiary industry to substitute the dependence of secondary industry.

(4)Beijing-Tianjin-Hebei economic belt can improve energy intensity of secondary industry as the breakthrough on reducing energy consumption. Moreover, share economy plays a key role. For example, invest more R\&D fees on secondary industry, abandon backward technology, and quicken industrialization process. Meanwhile, do as the technology centre, Beijing should improve the conversion rate of science and technology, and guide its researchers and other resources to support the development of Tianjin and Hebei in the integration process.

(5)Fuel structure of Beijing-Tianjin-Hebei economic belt is unreasonable. Therefore, Beijing should popularize renewable energy; Hebei and Tianjin ought to impair reliance on coal, and encourage the consumption of cleaner energy by the means of price and fiscal subsidy.

\section{Acknowledgments}

This study is supported by Beijing Natural Science Foundation (9172001) and "18 connotation development -resource, environment and circular economy" project(033000514118003).

\section{References}

[1] Yan H. Provincial energy intensity in China: The role of urbanization. Energy Policy. Vol. 86(2015), p.635-650.

[2] Zhang H, Lahr ML. China's energy consumption change from 1987 to 2007: A multi-regional structural decomposition analysis. Energy Policy. Vol. 67(2014), p.682-693.

[3] Yang G, Mingguang L. Analysis on the degree of the industrial structure's impact on the energy consumption--Based on empirical study of Guangdong Province. Energy Procedia. Vol.5(2011), p. 1488-1496.

[4] Wang W, Liu X, Zhang M, Song X. Using a new generalized LMDI (logarithmic mean Divisia index) method to analyze China's energy consumption. Energy. Vol.67 (2014), p.617-622.

[5] Shao C, Guan Y, Wan Z, Guo C, Chu C, Ju M. Performance and decomposition analyses of carbon emissions from industrial energy consumption in Tianjin, China. Journal of Cleaner Production. Vol.64 (2014), p. 590-601.

[6] Wang C, Liao H, Pan S, Zhao L, Wei Y. The fluctuations of China's energy intensity: Biased technical change. Applied Energy. Vol.135(2014), p.407-414.

[7] Zeng L, Xu M, Liang S, Zeng S, Zhang T. Revisiting drivers of energy intensity in China during 1997-2007: A structural decomposition analysis. Energy Policy. Vol.67(2014), p.640-647.

[8] Huebner GM, Hamilton I, Chalabi Z, Shipworth D, Oreszczyn T. Explaining domestic energy consumption - The comparative contribution of building factors, socio-demographics, behaviours and attitudes. Applied Energy. Vol.159 (2015), p.589-600.

[9] Yuxiang K, Chen Z. Government expenditure and energy intensity in China. Energy Policy. Vol.38(2010), p.691-694.

[10] Zhao X, Ma C, Hong D. Why did China's energy intensity increase during 1998-2006: Decomposition and policy analysis. Energy Policy. Vol.38(2010), p.1379-1388.

[11] Liu Z, Zhao T. Contribution of price/expenditure factors of residential energy consumption in China from 1993 to 2011: A decomposition analysis. Energy Conversion \& Management. Vol.98(2015), p.401-410.

[12] Lin B, Du K. Decomposing energy intensity change: A combination of index decomposition analysis and production-theoretical decomposition analysis. Applied Energy. Vol.129(2014), p.158-165. 
[13] Ang BW, Lee PW. Decomposition of industrial energy consumption: The energy coefficient approach. Energy Economics. Vol.18(1996), p.129-143.

[14] Ang BW. Monitoring changes in economy-wide energy efficiency: From energy-GDP ratio to composite efficiency index. Energy Policy. Vol.34(2006), p.574-582.

[15] Ang BW. Decomposition analysis for policymaking in energy. Energy Policy. Vol.32(2004), p.1131-1139. 